\title{
COMPETÊNCIAS INFORMACIONAIS NO ENSINO SUPERIOR
}

\author{
Dirce Maria Santin \\ Doutoranda em Comunicação e Informação \\ Universidade Federal do Rio Grande do Sul \\ dirsantin@yahoo.com.br
}

ASSOCIATION OF COLLEGE \& RESEARCH LIBRARIES (ACRL). Framework for information literacy for higher education. Chicago: ACRL, 2016.

Transcorridas quase duas décadas do desenvolvimento dos Padrões de Competência Informacional para o Ensino Superior (Information Literacy Competency Standards for Higher Education), publicados em 2000 pela Association of College \& Research Libraries (ACRL) e revogados em 2016, a ACRL disponibilizou um novo documento orientador sobre o tema: o Framework para a Competência Informacional para o Ensino Superior (Framework for Information Literacy for Higher Education). Iniciado em 2013, o Framework foi apresentado pelo Conselho da ACRL em fevereiro de 2015 e passou por diversas etapas de discussão, até ser aprovado em janeiro de 2016 e disponibilizado em junho do mesmo ano. Está disponível para acesso livre em: http://www.ala.org/acrl/standards/ilframe work.

A nova proposta parte da compreensão de que as diretrizes estabelecidas até então, compostas por cinco padrões e 22 indicadores, amplamente utilizadas por bibliotecas do mundo todo, tornaram-se obsoletas frente ao contexto acadêmico de rápida transformação e ao ecossistema dinâmico de informação. Mudanças na tecnologia, na comunicação científica e no ciclo de vida da informação estimularam a revisão dos pa- drões, além de preocupações pedagógicas. As novas configurações estabelecem novos desafios e exigem ideias e abordagens inovadoras em relação às competências informacionais no ensino superior.

O novo documento atribui maior ênfase aos papeis e responsabilidades de alunos, professores e bibliotecários no contexto acadêmico. Enquanto os alunos passam a ter maior autonomia e responsabilidade no acesso e no uso da informação, os professores têm maior responsabilidade na concepção de currículos e atribuições capazes de ampliar o envolvimento com as ideias fundamentais sobre a informação no âmbito de suas disciplinas. Aos bibliotecários cabe maior responsabilidade na concepção de ideias e programas que ampliem o aprendizado e as competências informacionais, contribuindo mais amplamente com professores e alunos.

A estrutura do Framework baseia-se num conjunto de seis conceitos nucleares, e não mais em orientações e aprendizados prescritivos em relação às competências como ocorria nos padrões do documento anterior. A ideia dos conceitos nucleares, com opções flexíveis de implementação a partir de disposições e práticas de conhecimento, é uma das principais inovações estruturais do documento.

Os conceitos nucleares do Framework organizam diversos outros conceitos e ideias sobre informação, pesquisa e formação acadêmica. Fundamentados na obra de Wiggins e McTigre (2004), os elementos conceituais 
relacionam-se aos currículos, mas também ultrapassam os limites das disciplinas e ampliam as possibilidades e os modos de pensar e usar a informação no meio acadêmico. $\mathrm{Na}$ perspectiva de Wiggins e McTigre (2004) o aprendizado é multifacetado, ou seja, há diferentes aspectos que compõem a compreensão dos conceitos, como há diferentes métodos de compreensão e metas intelectuais distintas. Para os autores, quando compreendemos de fato temos condições de explicar e interpretar fenômenos, fatos e dados, aplicar o conhecimento, ter perspectiva e enfatizar os conceitos, além de ter autoconhecimento. Essas facetas refletem as diferentes conotações de compreensão e podem orientar a seleção e o desenho de avaliações de aprendizado em contextos e situações diversas, como ocorre com o documento proposto pela ACRL.

Além dos conceitos nucleares, o modelo também é composto por elementos adicionais que ilustram importantes objetivos da aprendizagem: as práticas de conhecimentos, que exemplificam formas pelas quais os alunos podem ampliar o entendimento dos conceitos; e as disposições da competência informacional, que descrevem maneiras de abordar aspectos afetivos e atitudinais em relação à informação, valorizando as dimensões da aprendizagem.

O Framework organiza-se a partir dos conceitos nucleares, sendo que cada um deles é constituído pelo próprio conceito central, um conjunto de práticas e um conjunto de disposições. Os conceitos centrais do modelo são apresentados a seguir, na ordem alfabética do documento original, em inglês, conforme definido pela ACRL.

a) a autoridade é construída e contextual: os recursos de informação refletem a experiência e credibilidade de seus criadores e são avaliados com base nas necessidades e nos contextos de uso da informação. A autoridade é construída, é contextual, e as comunidades podem reconhecê-la de formas distintas;

b) criação de informação como um processo: as informações são produzidas para transmitir mensagens e são compartilhadas por meio de métodos diversos. Os processos iterativos de pesquisa, criação, revisão e divulgação da informação variam, e os produtos deles resultantes refletem essas diferenças;

c) a informação tem valor: a informação possui diversas dimensões de valor, inclusive como mercadoria, meio de educação ou de influência, e como recurso de negociação e compreensão do mundo. Os interesses jurídicos e socioeconômicos influenciam a produção e a disseminação da informação;

d) pesquisa como investigação: a pesquisa é iterativa e depende de fazer perguntas cada vez mais complexas ou novas, cujas respostas geram perguntas adicionais ou novas linhas de pesquisa em qualquer campo;

e) conhecimento em debate: comunidades acadêmicas envolvem-se em discursos sustentados por novas percepções e descobertas, que ocorrem ao longo do tempo, como resultado de perspectivas e interpretações variadas;

f) pesquisa como exploração estratégica: a busca por informação é muitas vezes não-linear e iterativa, exigindo a avaliação de uma ampla gama de fontes de informação e também flexibilidade mental para buscar caminhos alternativos à medida que novas compreensões se desenvolvem.

O Framework também tem por base o conceito de metacompetência informacional, que compreende um conjunto abrangente de habilidades de alunos, os quais são consumidores e criadores de informação (MACKEY; JACOBSON, 2011, 2014). A metacompetência compreenderia assim desde questões afetivas, comportamentais, cognitivas e metacognitivas até a autorreflexão crítica, elementos cruciais para se tornar autodirigido num ecossistema de informação em rápida mudança.

Independente dos debates em torno dos conceitos de competência e metacompe- 
tência informacional, observa-se o esforço do modelo em tornar mais ampla e flexível a própria compreensão de competência informacional no ensino superior. Nem as práticas de conhecimento nem as disposições que suportam os conceitos do Framework pretendem ser exaustivas e prescrever o que as bibliotecas e seus parceiros nas universidades devem fazer. Sugerem apenas alguns caminhos que as bibliotecas podem seguir, da forma mais adequada a cada situação, inclusive em relação à concepção de estratégias de aprendizagem.

O Framework abre novos desafios e oportunidades para bibliotecários e professores na concepção de cursos, programas e currículos. A colaboração entre os agentes da aprendizagem também ganha ênfase e pode resultar em propostas mais amplas, com maior envolvimento dos alunos e melhores resultados na avaliação do aprendizado. Outro destaque é a importância crescente das experiências dos próprios estudantes, que passam a ter maior autonomia e responsabilidade no acesso e uso da informação e também um papel cada vez mais ativo no processo de aprendizagem.

O Framework reconhece o processo de alfabetização informacional como um fenômeno social, em que os alunos são aprendizes participativos. Enquanto os padrões descreviam a alfabetização informacional com base em competências, a nova proposta a define como uma prática social. O enfoque nas interações sociais, baseado na filosofia construtivista social, torna a nova proposta menos redutora e mais inclusiva que a abordagem positivista, que percebia a informação como algo objetivo e mensurável. Entretanto, apesar das críticas aos padrões anteriores, especialmente no sentido de ignorar aspectos sociais e políticos da competência informacional, eles ainda têm forte influência e papel importante nas discussões sobre a competência informacional (FOASBERG, 2015).

A leitura atenta do Framework é fundamental para pesquisadores e bibliotecários que se dedicam ao estudo e ao trabalho com competências informacionais, em especial no ensino superior. É igualmente importante para professores dos diversos campos acadêmicos, dado que a informação é elemento central do processo de aprendizagem das diversas áreas do conhecimento. Os desafios e as oportunidades que se estabelecem para bibliotecários e bibliotecas acadêmicas a partir do estudo do Framework são realmente significativos, como são significativas as contribuições do modelo para o aprimoramento de competências informacionais no ensino superior.

A ACRL produz diversos padrões e diretrizes para as bibliotecas acadêmicas e o Framework é uma de suas contribuições recentes mais significativas. A Associação atua como líder mundial nas discussões sobre competência informacional no ensino superior e incentiva a colaboração entre os agentes, inclusive pelo compartilhamento de recursos de instrução em repositório on-line desenvolvido para esta finalidade (http://sandbox.acrl.org). Outro exemplo é o blog criado pela ACRL para fomentar o uso do Framework e de conteúdos relacionados, além de incentivar o compartilhamento de experiências (http://acrl.ala.org/framework). Portanto, a ACRL conta com a liderança e a autoridade necessárias para a proposição do modelo, que, assim como o anterior, tente a gerar debates, reflexões e importantes ações em instituições do mundo todo.

Artigo recebido em 31/01/2018 e aceito para publicação em 01/05/2018

\section{REFERÊNCIAS}

ASSOCIATION OF COLLEGE \& RESEARCH LIBRARIES. Framework for information literacy for higher education. Chicago, 2015. Disponível em:
$<$ http://www.ala.org/acrl/standards/ilfram ework>. Acesso em: 05 jan. 2018.

ASSOCIATION OF COLLEGE \& RESEARCH LIBRARIES. Information literacy competency standards for higher 
education. Chicago, 2000. Disponível em: $<$ http://www.ala.org/acrl/standards/infor mationliteracycompetency $>$. Acesso em: 05 jan. 2018.

FOASBERG, N. M. From Standards to Frameworks for IL: how the ACRL Framework addresses critiques of the Standards.

Portal: Libraries and the Academy, Baltimore, v. 15, n. 4, p. 699-717, 2015. Disponível em:

$<$ https://academicworks.cuny.edu/qc_pubs /14>. Acesso em: 23 jan. 2018.
MACKEY, T. P.; JACOBSON, T. E. Reframing Information Literacy as a Metaliteracy. College $\&$ Research Libraries, Chicago, v. 72, n. 1, p. 62-78, 1 jan. 2011.

MACKEY, T. P.; JACOBSON, T. E. Metaliteracy: reinventing information literacy to empower learners. Chicago: ALA NealSchuman, 2014.

WIGGINS, G.; MCTIGHE, J. Understanding by design. Alexandria: Association for Supervision and Curriculum Development, 2004. 